\title{
Spanish consensus on treat to target for osteoporosis
}

\author{
X. Nogués ${ }^{1}$ - J. M. Nolla ${ }^{2}$ E. Casado ${ }^{3}$ - E. Jódar ${ }^{4} \cdot$ M. Muñoz-Torres ${ }^{5}$. \\ J. M. Quesada-Gómez ${ }^{6} \cdot$ L. Canals $^{7} \cdot$ M. Balcells ${ }^{7} \cdot$ L. Lizán $^{8}$
}

Received: 1 June 2017 / Accepted: 8 November 2017 /Published online: 24 November 2017

(C) The Author(s) 2017. This article is an open access publication

\begin{abstract}
Summary To reach a Spanish expert consensus on a treat-totarget strategy in osteoporosis, a Delphi Consensus Study has been developed. Most of the experts (59.8\%) were rheumatologist with a mean clinical experience of 21.3 years (SD 8.5). Consensus was achieved for $70 \%$ of the items. Therapeutic objectives, patient follow-up scheme, treatment failure criteria, and appropriate treatment choice for use in T2 T strategy in Spain have been defined.
\end{abstract}

\section{Nogués}

XNogues@parcdesalutmar.cat

1 Mar Institute of Medical Research (IMIM), Centro de Investigación Biomédica en Red de Fragilidad y Envejecimiento Saludable (CIBERFES), Universitat Autonòma de Barcelona , Barcelona, Spain

2 IDIBELL-University Hospital Bellvitge, L'Hospitalet de Llobregat, Spain

3 Parc Taulí Universtiy Hospital, Institut d'Investigació i Innovació Parc Taulí I3PT, Universitat Autònoma de Barcelona, Sabadell, Spain

4 University Hospital Quirón Salud, Universidad Europea de Madrid, Madrid, Spain

5 Bone Metabolic Unit, UGC Endocrinología y Nutrición, Hospital Universitario Campus de la Salud de Granada, Instituto de Investigación Biosanitaria ibs, Centro de Investigación Biomédica en Red de Fragilidad y Envejecimiento Saludable (CIBERFES), Granada, Spain

6 UGC Endocrinología y Nutrición, Centro de Investigación Biomédica en Red de Fragilidad y Envejecimiento Saludable (CIBERFES), University Hospital Reina Sofía \& IMIBIC, Córdoba, Spain

7 Amgen, Barcelona, Spain

8 Outcomes'10, Department of Medicine, University Jaume I, Castelló de la Plana, Spain
Introduction The paper aims to achieve a Spanish expert consensus on a treat-to-target (T2T) strategy in osteoporosis.

Methods A scientific committee led the project and was involved in expert panel identification and Delphi questionnaire development. Two Delphi rounds were completed. The firstround questionnaire included 24 items and assessed, using a seven-point Likert scale, the experts' wish (W) and prognosis (P) in 5 years for each topic (applicability, therapeutic objectives, patient follow-up, and possible treatment to be prescribed). Items for which there was no consensus in the first round were included in the second round. Consensus was defined as $\geq 75 \%$ agreement (somewhat/mostly/entirely agree) or disagreement (somewhat/mostly/entirely disagree) responses. Results Of the experts, 112 and 106 completed the first and second rounds, respectively. $59.8 \%$ were rheumatologists with a mean clinical experience of 21.3 years (SD 8.5). Consensus was achieved for $70 \%$ of the items, and was established regarding the utility of a T2T strategy to define therapeutic objectives, optimal follow-up, and therapeutic algorithm. Participants agreed on the utility of the bone mineral density (BMD) value (T-score $>-2.5 \mathrm{SD}$ for spine and $>-2.5 /-2.0 \mathrm{SD}$ for femoral neck), lack of fractures, and fracture risk (FRAX) as therapeutic objectives. For measuring BMD changes, consensus was achieved on the suitability of hip and femoral neck locations. Experts agreed to consider treatment failure as when a significant BMD gain could not be achieved, or when a new fracture occurs within 2-3 years. There was consensus that all proposed therapies should achieve a therapeutic target through T2T strategy (treatments with the highest consensus scores were denosumab and teriparatide).

Conclusion The therapeutic objectives, patient follow-up scheme, treatment failure criteria, and appropriate treatment choice for use in T2T strategy in Spain have been established by a panel of experts. Some aspects nevertheless still require further analysis. 
Keywords Management - Osteoporosis · Osteoporosis care · Treatment - Treatment failure $\cdot$ Treat to target $\cdot$ Treat-to-target strategy

\section{Introduction}

Osteoporosis is a highly prevalent chronic disease characterized by decreased bone strength, the main clinical consequence of which is fragility fracture [1]. Drug treatment for osteoporosis is based on the presence of fragility fractures, measurement of bone mineral density (BMD), or fracture-risk assessment, usually determined by the Fracture Risk Assessment Tool (FRAX) score. Patients are monitored in clinical practice by measurements of BMD and, occasionally, bone-turnover markers (BTMs). A therapeutic intervention is deemed successful if no new fractures occur, BMD increases or remains stable, and BTMs change appropriately. There is still controversy, however, as to whether treatment should be maintained indefinitely under these circumstances [2]. In contrast, many other chronic diseases (e.g., diabetes, hypertension, dyslipidemia, and rheumatoid arthritis) have well-established treatment goals with which to facilitate the medical management of the disease, thus enabling a "treat-to-target" (T2T) strategy [3].

A biomarker is a measure that is indicative of a physiological process, a disease process, or a pharmacological response to an intervention. In order to establish a T2T strategy, it is first of all necessary to identify an appropriate biomarker for the disease follow-up process and to establish its threshold. Recently, some authors and scientific societies (such as the International Osteoporosis Foundation (IOF) and the American Society for Bone and Mineral Research (ASBMR)) have proposed that a T2T strategy could be helpful for osteoporosis treatment [4-6]. The general aim of T2T is to simplify management, and ultimately to reduce organ damage and improve clinical outcomes [4]. In particular, in the field of osteoporosis, T2T strategy is intended to individualize the initial choice of treatment based on the probability of achieving the goal for a patient. Moreover, decisions about stopping, discontinuing, changing, or continuing treatment may be also based on an established therapeutic target. Analyses of data available in the main placebo-controlled randomized trials with fracture as a primary endpoint could be the most suitable approach for identifying the best targets. However, the performance of biomarkers available for a T2T strategy has been questioned by some authors on the grounds that it is not easy to implement [7]. There are no established consensus goals for BMD, BTM, or fracture risk in the treatment of osteoporosis. Recently, societies such as ASMBR and the United States National Osteoporosis Foundation (NOF) have encouraged the idea of performing further comparative studies and analyses to define treatment goals in order to apply T2T strategy [8]. Fortunately, the significant impact of new anti-osteoporotic drugs on enhancing BMD and its relationship with lowering fracture risk could change this scenario [9].

In the present situation, the development of a comprehensive process for yielding consensus among experts in osteoporosis is the best approach for establishing a T2 T strategy and for assessing its possible future implementation in clinical practice. Delphi technique was therefore implemented to analyze the degree of consensus on T2T strategy in osteoporosis among Spanish specialists.

\section{Methods}

Two Delphi rounds were performed to establish consensus regarding the T2T strategy in osteoporosis. The Delphi technique is a structured method widely used to gather important information on a specific topic. It is based on a series of questionnaires or "rounds" addressed to experts. The key features of this method are the anonymity of participants and controlled feedback [10-12].

\section{Scientific committee}

The project was led by a scientific committee that was composed of six experts in bone metabolism (three endocrinologists, two rheumatologists, and one medical internist), who were selected by the main medical societies in bone metabolism (Spanish Society of Bone and Mineral Metabolism Research [SEIOMM] and Spanish Rheumatology Society [SER]). The scientific committee took part in the identification of the study participants (expert panel) and assisted in drawing up, reviewing, and approving the specific questionnaire developed for use during the Delphi rounds. Its members likewise validated and analyzed the results of the study.

\section{Expert panel}

The scientific committee selected 165 participants. The criteria for their selection included professional knowledge and experience in the field of osteoporosis, and practice in the Spanish Health System, as well as active membership of any of the scientific societies that collaborated in the study (henceforth they are referred to as experts).

There is little consensus in the literature concerning the optimal sample size of a Delphi study [13-15]. Some studies showed that experts who have similar training and general understanding in the field of interest allow for effective and reliable utilization of a small sample [16]. 


\section{Questionnaire}

The development of the first-round questionnaire involved a systematic review of the literature on osteoporosis, including articles referring to T2T. Once the main aspects of this strategy were identified, a discussion group defined the aspects to be included in the questionnaire with the scientific committee.

The first round of the electronic questionnaire included 24 items (176 aspects) involved in the T2T strategy on osteoporosis. These were distributed in four blocks: (1) applicability, (2) therapeutic objectives to be established, (3) patient followup, and (4) possible treatment to be prescribed. All items were drafted as assertions to be answered from two perspectives: wish (desire for it to happen) and prognosis (belief that it will happen) in a 5-year period. A seven-point Likert scale was used for each answer (entirely disagree/mostly disagree/somewhat disagree/neither agree nor disagree/somewhat agree/ mostly agree/entirely agree). An open space in which to express any opinions was also provided.

It is important to consider that questions included in blocks 1,2 , and 3 were raised on a general basis and with no reference to a specific drug.

\section{Definition of consensus}

Definition of consensus was established before data analyses. It was determined that consensus would be achieved if at least $75 \%$ of participants reached agreement (entirely agree, mostly agree, or somewhat agree) or disagreement (entirely disagree, mostly disagree, or somewhat disagree) [11, 17, 18]. The consensus regarding agreement or disagreement was considered to be strong when over $75 \%$ of the participants responded entirely agree/mostly agree or entirely disagree/mostly disagree [18].

\section{Chronogram of Delphi rounds}

The first round took place between 11 and 27 May 2015. The aspects about which respondents did not reach consensus in this first round (18 items that evaluated 78 aspects) were included in the second round. Accordingly, controlled feedback relating to ratings gathered from the group during the first round was provided for each item. Participants had the opportunity to alter their initial rating, based on the group responses. The second round took place between 8 and 21 June 2015 .

\section{Data analyses}

A database was created using SPSS Statistics version 20 by IBM (Armonk, NY, USA). Percentages for each response were calculated for both studied perspectives (wish and prognosis). A proportion within a range method was used to define consensus [11].

\section{Ethical aspects}

This study was performed in accordance with the Helsinki Declaration. All the personal data included in the study were dissociated from the results and kept anonymous, in compliance with Spanish law on data protection [19].

\section{Results}

\section{Participants' characteristics}

One-hundred and sixty-five experts from all over Spain were invited to participate by e-mail. Of these, 112 answered the first-round questionnaire (67.88\% of the experts contacted) and 106 the second-round questionnaire (including $94.6 \%$ of the experts who answered the first round). Of these, $65.2 \%$ were male, had a mean experience of 21.3 years (SD 8.5), and visited a median of 70 patients per month (IQR between 40 and 100). Most of the participants were rheumatologists (59.8\%), followed by internists $(14.3 \%)$ and endocrinologists $(10.7 \%)$.

\section{Achieved consensus}

Consensus was reached on $70 \%$ of issues, $44 \%$ of them being reached in the first Delphi round.

\section{a) Applicability of T2T strategy in osteoporosis}

Most of the participants (wish $96.4 \%$ and prognosis $82.1 \%$ ) agreed that, on the basis of T2T strategy, it should be possible to establish a well-defined therapeutic objective, to propose an optimal follow-up scheme, and to provide insight on the therapeutic strategy.

\section{b) Therapeutic objectives}

Assessment of the therapeutic objectives to be established in a T2T strategy for osteoporosis was based on 13 items (Table 1). There was consensus that the absence of new fractures, an increase in BMD, a significant change in BTMs, and fracture risk reduction measured by FRAX could be used as therapeutic objectives. Experts also agreed that all preceding parameters, except BTM, will be used in the next 5 years (Fig. 1). It is important to note that strong consensus was reached only on the use of absence of new fractures as a therapeutic objective (wish 93.8\%; prognosis $82.1 \%$ ) (Table 1 and Fig. 1).

As far as BMD is concerned, it was established that this should be measured using a tangible absolute value, or as a predetermined difference between two values. Scores higher than -2.5 SD were the only tangible absolute values for spine T-score, for which consensus was achieved from both the wish and prognosis perspectives. As far as femoral neck T-score 
Table 1 Results related to therapeutic objectives to be established in T2T strategy in osteoporosis

\begin{tabular}{|c|c|c|c|c|c|c|}
\hline \multirow[t]{2}{*}{ Question } & \multicolumn{3}{|c|}{ Wish $(\%)$} & \multicolumn{3}{|c|}{ Prognosis $(\%)$} \\
\hline & A & I & $\mathrm{D}$ & A & I & $\mathrm{D}$ \\
\hline \multicolumn{7}{|c|}{ For establishing a therapeutic objective, has to be considered } \\
\hline a. patient age & 97.3 & 0.9 & 1.8 & 98.2 & 0.9 & 0.9 \\
\hline b. baseline T-score & 94.6 & 1.8 & 3.6 & 94.6 & 2.7 & 2.7 \\
\hline \multicolumn{7}{|l|}{ The therapeutic objective is to be achieved } \\
\hline a. rapidly & 75.0 & 2.7 & 22.3 & 93.4 & 3.8 & 2. \\
\hline b. constantly and consistently maintained & 96.4 & 1.8 & 1.8 & 93.8 & 3.6 & 2 . \\
\hline
\end{tabular}

The following parameters could be used as therapeutic objectives in the context of the T2T strategy in osteoporosis

$\begin{array}{lrrrrrr}\text { a. BTM } & 86.8 & 3.8 & 9.4 & 60.6 & 10.4 & 29.2 \\ \text { b. BMD } & 91.1 & 0.9 & 8.0 & 91.1 & 6.3 & 2.7 \\ \text { c. fracture risk reduction measured FRAX } & 75.9 & 8.0 & 16.1 & 84.0 & 6.6 & 9.4 \\ \text { d. absence of new fractures } & 99.1 & - & 0.9 & 97.3 & 0.9 & 1.8 \\ \text { The BMD (measured with the T-score) has to be used as the } & 83.0 & 1.8 & 15.2 & 83.9 & 4.5 & 11.6\end{array}$
principal parameter for defining an adequate therapeutic objective in the context of the T2T strategy in osteoporosis

If $\mathrm{BMD}$ is used as the principal parameter for defining an adequate therapeutic objective, it has to be measured using a

$\begin{array}{lllllll}\text { a. tangible absolute value } & 88.7 & - & 11.3 & 92.5 & 0.9 & 6.6\end{array}$

b. predetermined difference between two values $\quad \begin{array}{lllllll} & 85.7 & 7.1 & 7.1 & 82.1 & 12.5 & 5.4\end{array}$

If BMD is used as the principal parameter for defining an adequate therapeutic objective, the target lumbar spine T-score to be achieved is

$\begin{array}{lrrrrrr}\text { a. >-2.5 SD } & 75.9 & 8.0 & 16.1 & 92.5 & 0.9 & 6.6 \\ \text { b. >-2.0 SD } & 64.3 & 13.4 & 22.3 & 53.6 & 24.1 & 22.3 \\ \text { c. >-1.5 SD } & 39.9 & 19.6 & 41.1 & 30.4 & 25.9 & 43.8 \\ \text { d. >-1.0 SD } & 24.1 & 21.4 & 54.5 & 18.8 & 22.3 & 58.9 \\ \text { e. an increment of 2 SD with reference to the baseline BMD } & 81.1 & 3.8 & 15.1 & 83.0 & 3.8 & 13.2 \\ \text { f. an increment in the basal BMD (any change) } & 86.8 & 2.8 & 10.4 & 86.8 & 4.7 & 8.5\end{array}$

If $\mathrm{BMD}$ is used as the principal parameter for defining an adequate therapeutic objective, the target femoral (femoral neck of total hip) T-score to be achieved is

$\begin{array}{lrrrrrr}\text { a. >-2.5 SD } & 79.5 & 3.6 & 17.0 & 79.5 & 7.1 & 13.4 \\ \text { b. >-2.0 SD } & 77.7 & 7.1 & 15.2 & 93.4 & 1.9 & 4.7 \\ \text { c. >-1.5 SD } & 46.4 & 14.3 & 39.3 & 38.4 & 22.3 & 39.3 \\ \text { d. >-1.0 SD } & 30.4 & 15.2 & 54.5 & 23.2 & 18.8 & 58.0 \\ \text { e. an increment of 2 SD with reference to the baseline BMD } & 84.9 & 4.7 & 10.4 & 84.0 & 3.8 & 12.3 \\ \text { f. an increment in the basal BMD (any change) } & 86.8 & 10.4 & 2.8 & 86.8 & 3.8 & 9.4\end{array}$

If fracture risk reduction is used as the principal parameter for defining an adequate therapeutic objective, it has to be measured using
a. FRAX
$\begin{array}{llllll}85.8 & 2.8 & 11.3 & 87.7 & 4.7 & 7.5\end{array}$
b. Q-fracture
$\begin{array}{llllll}59.4 & 24.5 & 16.0 & 31.1 & 54.7 & 14.2\end{array}$
c. Garvan
$28.3 \quad 40.6 \quad 31.1 \quad 9.4 \quad 74.5 \quad 16.0$

If fracture risk reduction is used as the principal parameter for defining an adequate therapeutic objective, it has to be measured using a
a. tangible percentage
$\begin{array}{llllll}89.6 & 2.8 & 7.5 & 91.5 & 2.8 & 5.7\end{array}$
b. predetermined difference between two values
$\begin{array}{llllll}86.8 & 4.7 & 8.5 & 87.7 & 5.7 & 6.6\end{array}$

If fracture risk reduction measured by FRAX is used as the principal parameter for defining an adequate therapeutic objective, the risk of major fractures (hip, vertebral, femur, humerus, and radius) has to be lower than
a. $5 \%$
$55.7 \quad 1.9$
42.5
$\begin{array}{lll}50.9 & 2.8 & 46.2\end{array}$
b. $7.5 \%$
$\begin{array}{ll}72.6 & 2.8\end{array}$
24.5
$63.2 \quad 5.7 \quad 31.1$
c. $10 \%$
$\begin{array}{lllllll}75.5 & 2.8 & 21.7 & 68.9 & 4.7 & 26.4\end{array}$
d. $20 \%$ 
Table 1 (continued)

\begin{tabular}{|c|c|c|c|c|c|c|}
\hline \multirow[t]{2}{*}{ Question } & \multicolumn{3}{|c|}{ Wish (\%) } & \multicolumn{3}{|c|}{ Prognosis $(\%)$} \\
\hline & $\mathrm{A}$ & I & $\mathrm{D}$ & A & I & $\mathrm{D}$ \\
\hline \multicolumn{7}{|c|}{$\begin{array}{l}\text { If the absence of new fractures is used as the principal parameter for defining an adequate therapeutic objective, } \\
\text { the incidence of fractures has to be measured using }\end{array}$} \\
\hline a. VFA & 83.0 & 10.7 & 6.3 & 92.5 & 0.9 & 6.6 \\
\hline b. height & 75.9 & 8.9 & 15.2 & 94.3 & 2.8 & 2.8 \\
\hline c. conventional X-ray & 88.4 & 5.4 & 6.3 & 83.9 & 8.0 & 8.0 \\
\hline $\begin{array}{l}\text { d. major nonvertebral fragility fracture (humerus, radius, and } \\
\text { femur) }\end{array}$ & 96.4 & 2.7 & 0.9 & 95.5 & 2.7 & 1.8 \\
\hline e. any fracture (including pelvic branches and other long bones) & 91.1 & 7.1 & 1.8 & 85.7 & 8.9 & 5.4 \\
\hline \multicolumn{7}{|l|}{ BTM are good therapeutic indicators for } \\
\hline a. determining the therapeutic objective & 79.2 & 5.7 & 15.1 & 64.2 & 5.7 & 30.2 \\
\hline b. selecting population to be treated & 29.2 & 5.7 & 65.1 & 21.7 & 5.7 & 72.6 \\
\hline c. establishing a therapeutic strategy & 52.8 & 9.4 & 37.7 & 43.4 & 9.4 & 47.2 \\
\hline d. performing treatment follow-up & 83.9 & 7.1 & 8.9 & 78.6 & 11.6 & 9.8 \\
\hline \multicolumn{7}{|c|}{$\begin{array}{l}\text { If BTM are used as the principal parameter for defining an adequate therapeutic objective, they have to be } \\
\text { measured using a }\end{array}$} \\
\hline a. tangible absolute value & 58.5 & 7.5 & 34.0 & 42.5 & 10.4 & 47.2 \\
\hline b. predetermined difference between two values & 79.5 & 10.7 & 9.8 & 95.3 & 3.8 & 0.9 \\
\hline
\end{tabular}

Italic values represent the most answered option

$A$ agreement, $I$ indifference, $D$ disagreement, wish (desire for it to happen), prognosis (belief that it will happen in a 5 -year period)

value was concerned, there was consensus that scores higher than -2.5 and -2.0 SD should be established as a therapeutic objective.

\section{c) Patient follow-up}

From both perspectives (wish and prognosis), there was consensus that the three anatomic areas suggested in the Delphi questionnaire (lumbar spine, femoral neck, and total hip) were useful for monitoring BMD in patients who have already been treated (Table 2). It is noteworthy that a strong consensus was established in both perspectives related to the usefulness of femoral neck area (wish 99.1\%; prognosis $98.2 \%)$.

Fig. 1 Reported expert agreement among therapeutic objectives to be established in T2T strategy

\section{d) Treatment prescribed}

Six items of the survey assessed matters related to the treatment prescribed in a hypothetical T2T strategy for osteoporosis (Table 3).

Participants deemed that all drugs, except strontium ranelate, were suitable for a T2T strategy.

According to expert opinion, the most suitable drug for this strategy is denosumab (for which there was over 97\% agreement), followed by teriparatide ( $96.4 \%$ agreement). There was, on the other hand, considerable disagreement, both regarding wish and prognosis, on whether strontium ranelate is a suitable drug for a $\mathrm{T} 2 \mathrm{~T}$ strategy.

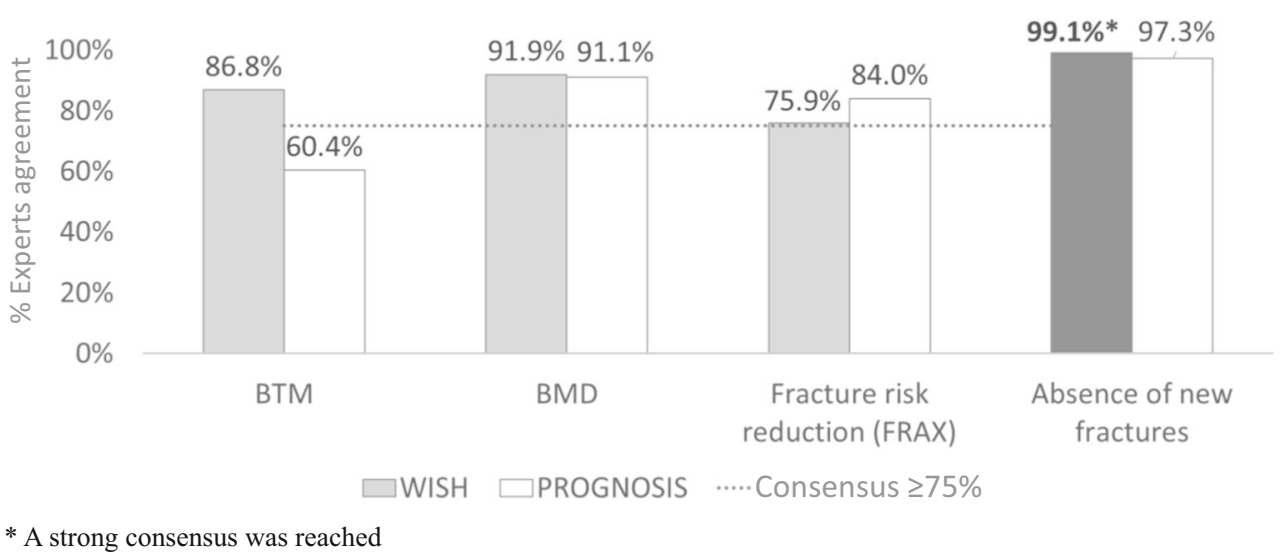


Table 2 Results related to follow-up of people with osteoporosis using a T2T strategy

\begin{tabular}{llllllll}
\hline Question & \multicolumn{2}{ll}{ Wish (\%) } & & & \multicolumn{2}{l}{ Prognosis (\%) } & \\
\cline { 2 - 3 } \cline { 5 - 7 } & A & I & D & & A & I & D \\
\hline
\end{tabular}

For monitoring the BMD in patients already treated, the following anatomic can be useful:

\begin{tabular}{lllllll} 
a. lumbar spine & 96.4 & 0.9 & 2.7 & 96.4 & 0.9 & 2.7 \\
b. femoral neck & 99.1 & - & 0.9 & 98.2 & 1.8 & - \\
c. total hip & 92.0 & 5.4 & 2.7 & 92.0 & 6.3 & 1.8 \\
\hline
\end{tabular}

Italic values represent the most answered option

$A$ agreement, $I$ indifference, $D$ disagreement, wish (desire for it to happen), prognosis (belief that it will happen in a 5 -year period)
A drug holiday following the achievement of a therapeutic objective seems a good strategy and achieved over $80 \%$ agreement, for bisphosphonates, strontium ranelate, and denosumab. However, when using selective estrogen-receptor modulator (SERM), there was no agreement on the best option after the objective has been achieved.

\section{e) Treatment failure}

From wish and prognosis perspectives, there was consensus that treatment failure should be considered whenever the BMD increment is not achieved within 2 or 3 years, a new fracture is diagnosed over 2 or 3 years, or a significant change in BTM is not achieved in the following 6 months or 1 year (Table 4 and Fig. 2).
Table 3 Results related to treatments to be prescribed in $\mathrm{T} 2 \mathrm{~T}$ strategy on osteoporosis

\begin{tabular}{|c|c|c|c|c|c|c|}
\hline \multirow[t]{2}{*}{ Question } & \multicolumn{3}{|c|}{ Wish $(\%)$} & \multicolumn{3}{|c|}{ Prognosis $(\%)$} \\
\hline & A & I & $\mathrm{D}$ & A & I & $\mathrm{D}$ \\
\hline \multicolumn{7}{|c|}{ The T2T strategy in osteoporosis is possible with the following anti-osteoporotic treatment: } \\
\hline a. oral bisphosphonates & 88.4 & 5.4 & 6.3 & 88.4 & 3.6 & 8.0 \\
\hline b. intravenous bisphosphonates & 92.0 & 6.3 & 1.8 & 89.3 & 6.3 & 4.5 \\
\hline c. SERM & 94.3 & 1.9 & 3.8 & 96.2 & - & 3.8 \\
\hline d. strontium ranelate & 76.4 & 5.7 & 17.9 & 58.5 & 4.7 & 36.8 \\
\hline e. denosumab & 97.3 & 1.8 & 0.9 & 94.6 & 3.6 & 1.8 \\
\hline f. teriparatide & 96.4 & 1.8 & 1.8 & 92.0 & 4.5 & 3.6 \\
\hline g. denosumab plus teriparatide & 80.4 & 11.6 & 8.0 & 78.6 & 10.7 & 10.7 \\
\hline h. developing treatments & 86.6 & 11.6 & 1.8 & 81.3 & 13.4 & 5.4 \\
\hline
\end{tabular}

In patients treated with bisphosphonates, once the therapeutic objective has been reached, the treatment has to be

$\begin{array}{lrrrrrr}\text { a. stopped for a period of time (drug holiday) } & 81.3 & 2.7 & 16.1 & 77.7 & 6.3 & 16.1 \\ \text { b. continued indefinitely } & 12.5 & 1.8 & 85.7 & 10.7 & 9.8 & 79.5 \\ \text { c. switched } & 5.7 & 1.9 & 92.5 & 5.7 & 1.9 & 92.5\end{array}$

In patients treated with SERM, once the therapeutic objective has been reached, the treatment has to be

$\begin{array}{llllllr}\text { a. stopped for a period of time (drug holiday) } & 34.0 & 3.8 & 62.3 & 36.8 & 4.7 & 8.5 \\ \text { b. continued indefinitely } & 16.1 & 7.1 & 76.8 & 17.0 & 8.0 & 75.0 \\ \text { c. switched } & 32.1 & 4.7 & 63.2 & 26.4 & 7.5 & 66.0\end{array}$

In patients treated with strontium ranelate, once the therapeutic objective has been reached, the treatment has to be $\begin{array}{lllllll}\text { a. stopped for a period of time (drug holiday) } & 84.0 & 7.5 & 8.5 & 83.0 & 8.5 & 8.5\end{array}$

$\begin{array}{lllllll}\text { b. continued indefinitely } & 8.9 & 8.0 & 83.0 & 8.9 & 10.7 & 80.4\end{array}$

$\begin{array}{lllllll}\text { c. switched } & 67.9 & 6.6 & 25.5 & 68.9 & 6.6 & 24.5\end{array}$

In patients treated with teriparatide, once the therapeutic objective has been reached, the treatment has to be

$\begin{array}{lllllll}\text { a. stopped for a period of time (drug holiday) } & 75.5 & 1.9 & 22.6 & 76.4 & 1.9 & 21.7\end{array}$

$\begin{array}{lllllll}\text { b. continued indefinitely } & 3.6 & 2.7 & 93.8 & 2.7 & 4.5 & 92.9\end{array}$

$\begin{array}{lllllll}\text { c. switched } & 80.4 & 3.6 & 16.1 & 77.7 & 5.4 & 17.0\end{array}$

In patients treated with denosumab, once the therapeutic objective has been reached, the treatment has to be

$\begin{array}{lrlrrrr}\text { a. stopped for a period of time (drug holiday) } & 81.1 & - & 18.9 & 84.9 & - & 15.1 \\ \text { b. continued indefinitely } & 8.5 & - & 91.5 & 6.6 & 0.9 & 92.5 \\ \text { c. switched } & 15.1 & 2.8 & 82.1 & 12.3 & 3.8 & 84.0\end{array}$

Italic values represent the most answered option

$A$ agreement, $I$ indifference, $D$ disagreement, wish (desire for it to happen), prognosis (belief that it will happen in a 5-year period) 
Table 4 Results related to therapeutic-failure definition

\begin{tabular}{|c|c|c|c|c|c|c|}
\hline \multirow[t]{2}{*}{ Question } & \multicolumn{3}{|c|}{ Wish $(\%)$} & \multicolumn{3}{|c|}{ Prognosis $(\%)$} \\
\hline & A & I & $\mathrm{D}$ & A & I & $\mathrm{D}$ \\
\hline \multicolumn{7}{|c|}{ Therapeutic failure is to be considered when the BMD increment is not achieved in } \\
\hline a. 6 months & 8.9 & 2.7 & 88.4 & 5.4 & 8.0 & 86.6 \\
\hline b. 1 year & 35.7 & 4.5 & 59.8 & 33.9 & 8.9 & 57.1 \\
\hline c. 2 years & 81.3 & 6.3 & 12.5 & 82.1 & 4.5 & 13.4 \\
\hline d. 3 years & 77.7 & 8.0 & 14.3 & 75.9 & 9.8 & 14.3 \\
\hline e. 5 years & 67.0 & 9.8 & 23.2 & 65.2 & 11.6 & 23.2 \\
\hline f. $>5$ years & 51.8 & 13.4 & 34.8 & 48.2 & 19.6 & 32.1 \\
\hline \multicolumn{7}{|c|}{ Therapeutic failure is to be considered when a new fracture is diagnosed in the following: } \\
\hline a. 6 months & 38.4 & 6.3 & 55.4 & 33.9 & 10.7 & 55.4 \\
\hline b. 1 year & 77.7 & 8.0 & 14.3 & 77.7 & 8.0 & 14.3 \\
\hline c. 2 years & 92.0 & 2.7 & 5.4 & 92.0 & 4.5 & 3.6 \\
\hline d. 3 years & 90.2 & 4.5 & 5.4 & 88.4 & 7.1 & 4.5 \\
\hline e. 5 years & 79.5 & 8.9 & 11.6 & 79.5 & 9.8 & 10.7 \\
\hline f. $>5$ years & 69.6 & 11.6 & 18.8 & 68.8 & 13.4 & 17.9 \\
\hline \multicolumn{7}{|c|}{$\begin{array}{l}\text { Therapeutic failure is to be considered when a significant change in bone-remodeling markers is not achieved } \mathrm{i} \\
\text { the following: }\end{array}$} \\
\hline a. 1 month & 1.9 & 3.8 & 94.3 & 0.9 & 3.8 & 95.3 \\
\hline b. 3 months & 73.6 & 4.7 & 21.7 & 59.4 & 6.6 & 34.0 \\
\hline c. 6 months & 75.0 & 16.1 & 8.9 & 93.4 & 2.8 & 3.8 \\
\hline d. 1 year & 90.6 & 4.7 & 4.7 & 89.6 & 5.7 & 4.7 \\
\hline e. 2 years & 68.9 & 4.7 & 26.4 & 67.9 & 5.7 & 26.4 \\
\hline f. $>2$ years & 65.1 & 2.8 & 32.1 & 61.3 & 4.7 & 34.0 \\
\hline
\end{tabular}

Italic values represent the most answered option

$A$ agreement, $I$ indifference, $D$ disagreement, wish (desire for it to happen), prognosis (belief that it will happen in a 5-year period)

\section{Discussion}

To our knowledge, this is the first expert consensus regarding the applicability of a T2T strategy for osteoporosis in clinical practice. The results of Spanish consensus on T2T strategy for osteoporosis using Delphi methodology are presented. The study results reflect data not only from pivotal studies but also from post-authorization studies and, above all, the clinical experience of experts.

A treating strategy with which to achieve a well-predefined goal is a feature of different areas of medicine. T2T strategy has thus been widely applied in the fields of diabetes [3],
Fig. 2 Reported expert agreement related to therapeutic failure definition

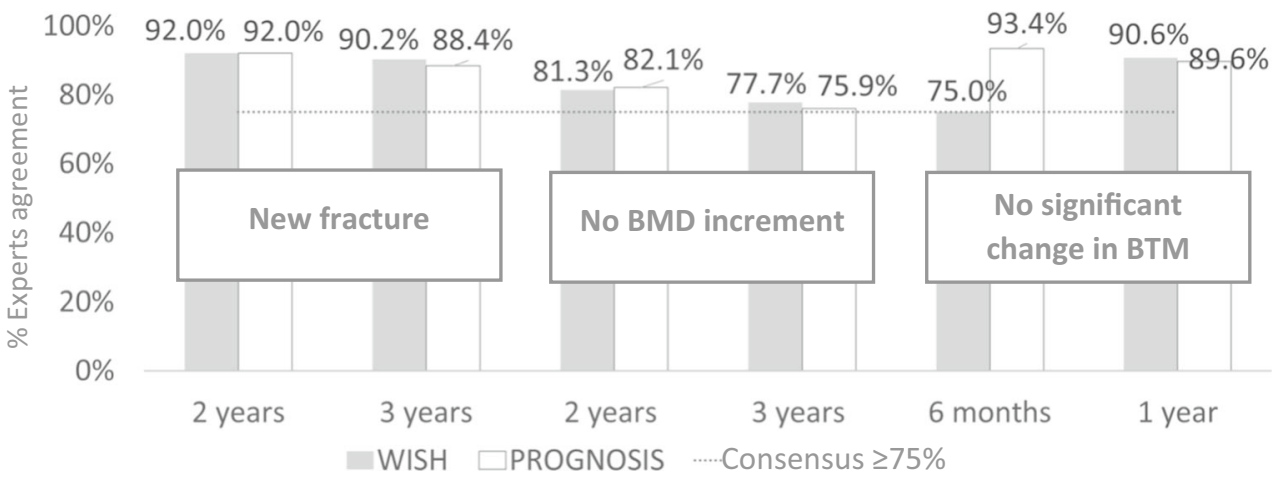


hypertension [20], hypercholesterolemia [21], and rheumatoid arthritis [22, 23]. In osteoporosis, it has also recently become a matter of interest. Its role in this context remains controversial. T2T is an attractive approach for application in order to avoid the perpetuation of treatment and possible adverse effects, provided that the desired goal is achieved. The problem begins when a measurable and sensitive tool is required to assess the achievement of the final objective. Capturing the change in fracture risk associated with treatment is not easy. Strong evidence is needed to confirm that selecting and switching treatment reduces fracture risk more effectively than the current standard of care [8].

Since we have treatments to modify the bone-remodeling process, the ultimate objective has always been the reduction of fragility fractures [1]. Given that two new issues have appeared in the field of osteoporosis, the need to establish a therapeutic goal has become evident [4]. Some treatments, such as anti-sclerostin or denosumab, have demonstrated a high increase in BMD after short periods of treatment, with most patients reaching normal range T-score values when evaluated by dual-energy X-ray absorptiometry (DXA) measurements $[24,25]$.

Until now, however, the measurable goal has never been attempted, and when it was attained, debate centered upon whether the treatment should be stopped, changed, or at least reconsidered, given that fragility fractures could reappear if some treatments were discontinued. We have therefore analyzed the current thinking of Spanish experts in bone metabolism, on the basis of two perspectives: the wish or desire for occurrence and the prognosis or belief that, upon consideration of the field and resources, this will be put into practice within a 5-year period.

Wide consensus arose when experts were asked about the feasibility of establishing a well-defined objective in osteoporosis. Almost all participants agreed on the possibility of applying T2T strategy in clinical practice in osteoporosis. Consensus usually arises in Delphi methodology when agreement or disagreement ranges from 50 to $80 \%$ [26]. In this case, agreement exceeded 95\%, which could indicate that Spanish physicians have a strong desire to have a T2T for osteoporosis management.

There was consensus that the parameters used as therapeutic objectives in the context of the T2T strategy in osteoporosis should be the absence of new fractures, a specific BMD value, and, at a lower level, BTM and fracture-risk reduction measured by FRAX. Many physicians do not have access to BTM and the use of FRAX is not general practice. Consequently, its implementation as a target is less feasible.

FRAX does not seem to be a good tool for measuring the reduction in fracture risk achieved with treatments. However, $75.9 \%$ of the experts would wish a therapeutic objective of a 10-year risk of fracture measured with a tool such as FRAX. Furthermore, $84 \%$ of them predicted that FRAX, probably with certain adjustments, will become a useful tool for a T2T strategy in osteoporosis. With regard to this hypothetical situation, Leslie et al. [27] demonstrated in the Manitoba cohort population that the increase in FRAX score over time after therapy was lessened, albeit not prevented. Actually, this hypothetical situation is almost impossible in the real life. In fact, Leslie et al. [27] demonstrated in the follow-up of Manitoba cohort that a small percentage of patients, even with a medication possession rate $>0.8$, achieved reduction in major fracture probability of $4 \%$ or higher. Therefore, we believe that the result of the question regarding FRAX reduction, even though it could be used as the principal parameter for defining an adequate therapeutic objective, is more a wish than a reality. It might reflect the desire of having in the future a tool more linked to a reduction of the risk in patients on treatment.

Consensus was established regarding the utility of BMD as a principal parameter for defining an adequate therapeutic objective. In line with that, it was established that BMD should be measured using a tangible absolute value, or as a predetermined difference between two values. Scores higher than $-2.5 \mathrm{SD}$ for spine T-score were the only tangible absolute values, for which there was consensus for both perspectives. As far as femoral neck T-score value is concerned, there was consensus that scores of over -2.5 or $-2.0 \mathrm{SD}$, which are almost the same threshold values for osteopenia and osteoporosis in the WHO definition [28], should be established as a therapeutic objective. The FLEX study [29] showed that the $\mathrm{T}$ score -2.5 was the optimal point to be achieved in order to prevent new nonvertebral fractures. Moreover, the results suggested that there was no advantage in continuing with alendronate. In our study, a $\mathrm{T}$ score of -2.0 was included on the basis of the FREEDOM study [9]. The results of the FREEDOM study suggested that the reduction of nonvertebral fracture risk associated with denosumab was influenced by the hip BMD achieved with initial therapy [9].

There was discussion regarding the $\mathrm{T}$-score threshold and the site of BMD measurement. It seems that spine BMD is influenced by several artifacts such as osteophytes, vascular calcifications, and sclerosis, and such factors could bias the real results [30]. Femoral-neck BMD, meanwhile, reflects more cortical bone, whereas total hip measures cortical and trabecular bone [31]. The first step to establish a measurable mark for T2T strategy would therefore be to select the proper location for measuring BMD. Despite all these technical considerations, when asked about the most appropriate anatomic locations for monitoring BMD in the Delphi questionnaire, consensus was reached on lumbar zone, femoral neck, and total hip, while only femoral-neck area saw strong consensus for both perspectives (wish and prognosis).

When fracture-risk reduction was used as the main parameter for defining an adequate therapeutic objective, there was agreement that this parameter should be measured using 
FRAX. Like BMD, there was consensus that fracture risk reduction should be measured either using a tangible percentage or as a predetermined difference between two values. As far as the former is concerned, consensus was only achieved on the value of risk of major fractures attained to be lower than $10 \%$. It is noteworthy that consensus was not established for the perspective of prognosis.

As regards BTM, there was consensus that they were good therapeutic indicators for determining the therapeutic objective and performing treatment follow-up. However, from the perspective of prognosis, consensus was established only on their utility in treatment follow-up.

For both perspectives, there was consensus concerning the utility of all parameters/techniques proposed for the measurement of incidence of new fractures: vertebral fracture analysis (VFA), height, conventional X-ray, major peripheral fragility fractures, or any fracture.

With regard to the optimal follow-up scheme, our results suggest that the best anatomic site for monitoring densitometry was the femoral neck, although lumbar spine obtained also a high participant wish score. In fact, this reflects the expertise of participants in the Delphi study, because it is well known that as precision and reproducibility are lower at lumbar spine, osteoarthritis and other artifacts might affect results in older people, and therefore, in these cases, femoral neck could be a better choice for measurement [32].

Experts reached consensus regarding the possibility of applying the T2T strategy in osteoporosis when the treatments used are oral bisphosphonates, intravenous bisphosphonates, and SERMs such as raloxifene or bazedoxifene, strontium ranelate, denosumab, teriparatide, denosumab plus teriparatide, or developing drugs. There was no consensus with regard to the perspective of prognosis when strontium ranelate was used. This result can perhaps be explained by the fact that even though the studies with strontium ranelate show a clear increase in BMD, its use has recently been restricted and there is a chance that the drug will be removed from the Spanish market.

The treatments for which the wish consensus scores were highest were denosumab and teriparatide. This result could be associated with its positive impact that has been reported in recent studies published after long-term treatment with denosumab alone [20, 33] or with combinations [34].

In reference to the treatment period, the experts agreed that regardless of the treatment used, once the therapeutic objective is accomplished, treatment should be stopped for a period of time, and also disagreed that treatment should be administrated indefinitely. It should be mentioned that no consensus was achieved when SERM was used. Meanwhile, in the case of teriparatide, there was also consensus on changing the treatment when, following recommendations to discontinue treatment, 18 or 24 months were achieved. Additionally, this point reflects the experience of participants, as these results are consistent with recent publications $[35,36]$. BMD monitorization after target accomplishment by reversible drugs such as denosumab would require further investigation. Denosumab is characterized by reversal of effect, and is associated with a progressive increase in vertebral fracture risk rate to levels comparable with before the start of treatment. Consequently, in order to prevent new factures, as has been reported by Anastasilakis et al. [37], those who discontinue denosumab should switch to another therapy after the 6 months dosing interval [38, 39]. There was consensus regarding therapeutic failure upon inability to achieve a clinically significant increase of BMD for 2 or 3 years, when a new fracture was diagnosed in the subsequent 1 to 5 years, or when a significant change in BTM was not achieved in the following 6 months or 1 year.

\section{Strength and limitations}

This study has several strengths and limitations. The main limitation is related to the scope of the study, as it was performed in Spain and the results may not be applicable to other countries. It would be interesting to undertake a similar study using the Delphi methodology with international experts and to observe and compare the results.

The main strength of the study is related to the expertise of the participants, as most of them were expert physicians with long experience in osteoporosis and a large number of visits per month. It is also important to note that high levels of consensus were achieved in the first round, when participants were unaware of other participants' responses.

Although the European Society for Clinical and Economic Aspects of Osteoporosis and Osteoarthritis (ESCEO) asserts that it is not currently feasible to apply a T2T strategy in osteoporosis, they did nevertheless identify a need to continue improving the treatment target for patients at higher risk ("target-to-treat strategy"). They consider that before approaching the real value of T2T strategy, it is necessary, among other matters, to establish an international consensus on intervention thresholds and a universally accepted definition regarding treatment failure. Other experts recommended the formation of a task force, composed of medical experts and representatives of physician and patient organizations, to explore the feasibility of establishing osteoporosis treatment targets.

\section{Conclusions}

A wide and representative panel of experts established consensus regarding therapeutic objectives, patient follow-up 
scheme, treatment-failure criteria, and appropriate treatment choice to use in T2T strategy in Spain. Although there are some aspects that require further analysis, this study provides new original data, based on Delphi methodology, with which to implement T2T strategy for the management of osteoporosis in Spain.

Acknowledgments The authors are very grateful to all the professionals who took part in the Delphi consultation rounds for their highly enriching contributions and enthusiastic participation.

\section{Compliance with ethical standards}

Conflicts of interest The project received financial support from Amgen S.A. to conduct the study. LC and MB work at Amgen S.A. and hold stock in Amgen. LL works at a Life Science Boutique that received funding from Amgen S.A. to coordinate and conduct the study and to write up the manuscript. MMT has received research grants from UCB and MSD; is a consultant for Amgen, Lilly, and UCB; and speakers' bureau member for Amgen and Lilly. EJ has received research grants from Amgen, Lilly, and MSD and consulting fees from Amgen, UCB, and Lilly. XN has received research grants from Lilly and Amgen; is a consultant for Lilly and Amgen; and speakers' bureau member for Lilly, Amgen, and MSD. JMN is a consultant for Abbvie, Amgen, BMS, Gebro, Lilly, MSD, Roche, Sandoz, and UCB and speakers' bureau member for Abbvie, Amgen, BMS, Gebro, Lilly, MSD, Roche, and UCB. JMQ has received research grants from Amgen, Lilly, FIS Carlos III, RETICEF, and Intensification of Investigation Junta de Andalucía; is a consultant for Amgen, MSD, Italfarmaco, and FAES; and speakers' bureau member for Amgen, MSD, Italfarmaco, and FAES. EC has participated in the speakers' bureau for Amgen, Lilly, MSD, FAES, and Rubió. All authors declare that all the results presented in the manuscript are the true expression of findings and there has been no interference in respondents' free communication and dissemination.

Open Access This article is distributed under the terms of the Creative Commons Attribution-NonCommercial 4.0 International License (http:// creativecommons.org/licenses/by-nc/4.0/), which permits any noncommercial use, distribution, and reproduction in any medium, provided you give appropriate credit to the original author(s) and the source, provide a link to the Creative Commons license, and indicate if changes were made.

\section{References}

1. NIH Consensus Development Panel (2001) Osteoporosis prevention, Diagnosis, and therapy. JAMA 285:785-795

2. Miller PD (2016) Underdiagnoses and undertreatment of osteoporosis: the battle to be won. J Clin Endocrinol Metab 10(3):852-859

3. Inzucchi SE, Bergenstal RM, Buse JB, Diamant M, Ferrannini E, Nauck M, Peters AL, Tsapas A, Wender R, Matthews DR (2015) Management of hyperglycemia in type 2 diabetes, 2015: a patientcentered approach: update to a position statement of the American Diabetes Association and the European Association for the Study of Diabetes. Diabetes Care 38(1):140-149. https://doi.org/10.2337/ dc14-2441

4. Lewiecki EM, Cummings SR, Cosman F (2013) Treat-to-target for osteoporosis: is now the time? J Clin Endocrinol Metab 98(3):946953. https://doi.org/10.1210/jc.2012-3680
5. Cummings SR, Cosman F, Eastell R, Reid IR, Mehta M, Lewiecki EM (2013) Goal-directed treatment of osteoporosis. J Bone Miner Res 28(3):433-438. https://doi.org/10.1002/jbmr.1854

6. Chapurlat R. (2016) Is it time for treat to target strategy in osteoporosis?. Joint Bone Spine

7. Kanis JA, McCloskey E, Branco J, Brandi ML, Dennison E, Devogelaer JP, Ferrari S, Kaufman JM, Papapoulos S, Reginster JY, Rizzoli R (2014) Goal-directed treatment of osteoporosis in Europe. Osteoporos Int 25(11):2533-2543. https://doi.org/10. 1007/s00198-014-2787-1

8. Cummings SR, Cosman F, Lewiecki EM, Schousboe JT, Bauer DC, Black DM, Brown TD, Cheung AM, Cody K, Cooper C, Diez-Perez A, Eastell R, Hadji P, Hosoi T, De Beur SJ, Kagan R, Kiel DP, Reid IR, Solomon DH, Randall S (2017) Goal-directed treatment for osteoporosis: a progress reported from the ASMBRNOF Working Group on goal-directed treatment for osteoporosis. J Bone Miner Res 32(1):3-10. https://doi.org/10.1002/jbmr.3039

9. Ferrari S, Adachi JD, Lippuner K, Zapalowski C, Miller PD, Reginster JY, Törring O, Kendler DL, Daizadeh NS, Wang A, O'Malley CD, Wagman RB, Libanati C, Lewiecki EM (2015) Further reductions in nonvertebral fracture rate with long-term denosumab treatment in the FREEDOM open-label extension and influence of hip bone mineral density after 3 years. Osteoporos Int 26(12):2763-2771. https://doi.org/10.1007/s00198-015-3179-x

10. Hsu CC, Sandford BA (2007) The Delphi technique: making sense of consensus. Practical assess. Res Eval 12:1-8

11. Diamond IR, Grant RC, Feldman BM, Pencharz PB, Ling SC, Moore AM, Wales PW (2014) Defining consensus: a systematic review recommends methodologic criteria for reporting of Delphi studies. J Clin Epidemiol 67(4):401-409. https://doi.org/10.1016/j. jclinepi.2013.12.002

12. Von der Gracht H (2012) Consensus measurement in Delphi studies: review and implications for future quality assurance. Technol Forecast Soc 79(8):1525-1536. https://doi.org/10.1016/j.techfore. 2012.04.013

13. Williams PL, Webb C (1994) The Delphi technique: a methodological discussion. J Adv Nurs 19:180-186 2

14. Fischer RG (1978) The Delphi method: a description, review and criticism. J Acad Librariansh 1978 4(2):64-70

15. Wilhelm WJ (2001) Alchemy of the Oracle: the Delphi technique. Delta Pi Epsilon J 43(1):6-26

16. Akins RB, Tolson H, Cole BR (2005) Stability of response characteristics of a Delphi panel: application of bootstrap data expansion. BMC Med Res Methodol 5:37

17. Hansen MP, Bjerrum L, Gharn-Hansen B, Jarbol DE (2010) Quality indicators for diagnosis and treatment of respiratory tract infections in general practice: a modified Delphi study. Scand J Public Healt 28:4-11

18. Lai L, Flower A, Moore M, Lewith G (2015) Developing clinical practice guidelines for Chinese herbal treatment of polycystic ovary syndrome: a mixed-methods modified Delphi study complement. Ther Med 23(3):430-438

19. Ley orgánica 15/1999, de 13 de diciembre, de Protección de Datos de Carácter Personal. BOE núm 298 de 14 de Diciembre de 1999

20. Mancia G, Fagard R, Narkiewicz K, ESH/ESC Task Force for the Management of Arterial Hypertension (2013) 2013 ESH/ESC guidelines for the management of arterial hypertension: the Task Force for the management of arterial hypertension of the European Society of Hypertension (ESH) and of the European Society of Cardiology (ESC). J Hypertens 31(7):1281-1357. https://doi.org/ 10.1097/01.hjh.0000431740.32696.cc

21. Catapano AL, Reiner Z, De Backer G, Graham I, Taskinen MR, Wiklund O, Agewall S, Alegria E, Chapman M, Durrington P, Erdine S, Halcox J, Hobbs R, Kjekshus J, Filardi PP, Riccardi G, Storey RF, Wood D, European Society of Cardiology (ESC); European Atherosclerosis Society (EAS) (2011) ESC/EAS 
guidelines for the management of dyslipidaemias: the Task Force for the management of dyslipidaemias of the European Society of Cardiology (ESC) and the European Atherosclerosis Society (EAS). Atherosclerosis 217(1):3-46

22. Smolen JS, Breedveld FC, Burmester GR, Bykerk V, Dougados M, Emery P, Kvien TK, Navarro-Compán MV, Oliver S, Schoels M, Scholte-Voshaar M, Stamm T, Stoffer M, Takeuchi T, Aletaha D, Andreu JL, Aringer M, Bergman M, Betteridge N, Bijlsma H, Burkhardt H, Cardiel M, Combe B, Durez P, Fonseca JE, Gibofsky A, Gomez-Reino JJ, Graninger W, Hannonen P, Haraoui B, Kouloumas M, Landewe R, Martin-Mola E, Nash P, Ostergaard M, Östör A, Richards P, Sokka-Isler T, Thorne C, Tzioufas AG, van Vollenhoven R, de Wit M, van der Heijde D (2016) Treating rheumatoid arthritis to target: 2014 update of the recommendations of an international task force. Ann Rheum Dis 75(1):3-15. https://doi.org/10.1136/annrheumdis-2015-207524

23. Smolen JS (2016) Treat-to-target as an approach in inflammatory arthritis. Curr Opin Rheumatol 28(3):297-302. https://doi.org/10. 1097/BOR.0000000000000284

24. Ominsky MS, Vlasseros F, Jolette J, Smith SY, Stouch B, Doellgast G, Gong J, Gao Y, Cao J, Graham K, Tipton B, Cai J, Deshpande R, Zhou L, Hale MD, Lightwood DJ, Henry AJ, Popplewell AG, Moore AR, Robinson MK, Lacey DL, Simonet WS, Paszty C (2010) Two doses of sclerostin antibody in cynomolgus monkeys increases bone formation, bone mineral density, and bone strength. J Bone Miner Res 25(5):948-959. https://doi.org/10.1002/jbmr.14

25. McClung MR, Lewiecki EM, Geller ML, Bolognese MA, Peacock M, Weinstein RL, Ding B, Rockabrand E, Wagman RB, Miller PD (2013) Effect of denosumab on bone mineral density and biochemical markers of bone turnover: 8-year results of a phase 2 clinical trial. Osteoporos Int 24(1):227-235. https://doi.org/10.1007/ s00198-012-2052-4

26. Rayens MK, Hahn EJ (2000) Building consensus using the policy Delphi method. Policy Polit Nurs Pract 1(4):308-315. https://doi. org/10.1177/152715440000100409

27. Leslie WD, Majumdar SR, Lix LM, Morin SN, Johansson H, Odén A, McCloskey EV, Kanis JA (2014) Can change in FRAX score be used to "treat to target"? A population-based cohort study. J Bone Miner Res 29(5):1074-1080. https://doi.org/10.1002/jbmr.2151

28. World Health Organisation 1994 Assessment of fracture risk and its application to screening for postmenopausal osteoporosis. Technical Report Series. WHO, Geneva

29. Black DM, Schwartz AV, Ensrud KE, Cauley JA, Levis S, Quandt SA, Satterfield S, Wallace RB, Bauer DC, Palermo L, Wehren LE, Lombardi A, Santora AC, Cummings SR, FLEX Research Group (2006) Effects of continuing or stopping alendronate after 5 years of treatment: the Fracture Intervention Trial Long-term Extension (FLEX): a randomized trial. JAMA 296(24):2927-2938

30. Gregson CL, Hardcastle SA, Cooper C, Tobias JH (2013) Friend or foe: high bone mineral density on routine bone density scanning, a review of causes and management. Rheumatology 52(6):968-985. https://doi.org/10.1093/rheumatology/ket007

31. Rivadeneira F, Zillikens MC, De Laet CE, Hofman A, Uitterlinden AG, Beck TJ, Pols HA (2007) Femoral neck BMD is a strong predictor of hip fracture susceptibility in elderly men and women because it detects cortical bone instability: the Rotterdam Study. J Bone Miner Res 22(11):1781-1790. https://doi.org/10.1359/jbmr. 070712

32. Khan AA, Brown JP, Kendler DL, Leslie WS, Lentle BC, Lewiecki EM, Miller PD, Nicholson LR, Olszynski WP, Watts NB (2002) The 2002 Canadian bone densitometry recommendations: takehome messages. CMAJ 167(10):1141-1145

33. Papapoulos S, Lippuner K, Roux C, Lin CJ, Kendler DL, Lewiecki EM, Brandi ML, Czerwiński E, Franek E, Lakatos P, Mautalen C, Minisola S, Reginster JY, Jensen S, Daizadeh NS, Wang A, Gavin M, Libanati C, Wagman RB, Bone HG (2015) The effect of 8 or 5 years of denosumab treatment in postmenopausal women with osteoporosis: results from the FREEDOM extension study. Osteoporos Int 26(12):2773-2783. https://doi.org/10.1007/ s00198-015-3234-7

34. Leder BZ, Tsai JN, Neer RM, Uihlein AV, Wallace PM, BurnettBowie SM. (2016) Response to therapy with teriparatide, denosumab, or both in postmenopausal women in the DATA (Denosumab and Teriparatide Administration) Study Randomized Controlled Trial. J Clin Densitom

35. Díez-Pérez A, Adachi JD, Adami S, Anderson FA Jr, Boonen S, Chapurlat R, Compston JE, Cooper C, Gehlbach SH, Greenspan SL, Hooven FH, LaCroix AZ, Nieves JW, Netelenbos JC, Pfeilschifter J, Rossini M, Roux C, Saag KG, Silverman S, Siris ES, Wyman A, Rushton-Smith SK, Watts NB, Global Longitudinal Study of Osteoporosis in Women (GLOW) Investigators (2014) Risk factors for treatment failure with antiosteoporosis medication: the global longitudinal study of osteoporosis in women (GLOW). J Bone Miner Res 29(1):260-267. https://doi.org/10.1002/jbmr.2023

36. Hawley S, Javaid MK, Rubin KH, Judge A, Arden NK, Vestergaard P, Eastell R, Diez-Perez A, Cooper C, Abrahamsen B, PrietoAlhambra D (2016) Incidence and predictors of multiple fractures despite high adherence to oral bisphosphonates: a binational population-based cohort study. J Bone Miner Res 31(1):234-244

37. Anastasilakis AD, Polyzos SA, Makras P, Aubry-Rozier B, Kaouri S, Lamy O (2017) Clinical features of 24 patients with reboundassociated vertebral fractures after denosumab discontinuation: systematic review and additional cases. J Bone Miner Res 32(6):12911296. https://doi.org/10.1002/jbmr.3110

38. Brown JP, Ferrari S, Gilchrist N, Jensen JEB, Pannacciulli N, Recknor C, Roux C, Smith S, Törring O, Valter I, Wagman RB, Wang A, Cummings S. Discontinuation of denosumab and associated vertebral fracture incidence: analysis from a phase 3 placebocontrolled study of denosumab and its open-label extension [abstract]. Arthritis Rheumatol 2016; 68 (suppl 10). http:// acrabstracts.org/abstract/discontinuation-of-denosumab-andassociated-vertebral-fracture-incidence-analysis-from-a-phase-3placebo-controlled-study-of-denosumab-and-its-open-labelextension/. Accessed February 9, 2017

39. Bone HG, Bolognese MA, Yuen CK, Kendler DL, Miller PD, Yang YC, Grazette L, San Martin J (2011) Gallagher JC. Effects of denosumab treatment and discontinuation on bone mineral density and bone turnover markers in postmenopausal women with low bone mass. J Clin Endocrinol Metab 96(4):972-980. https://doi. org/10.1210/jc.2010-1502 